\title{
Homenaje a Johann Wolfgang con motivo de su 250 aniversario
}

Marlene RALL Universidad Nacional Autónoma de México

Muy distinguido doctor Johann Wolfgang Goethe, Apreciado señor ministro y barón von Goethe, Ilustre poeta laureatus, príncipe de los poetas, anciano olímpico, Querido Don Wolfgang:

Con motivo de su 250 cumpleaños los aquí presentes quisiéramos rendirle un modesto homenaje, recordando sus incontables logros y méritos en el mundo de las ciencias y las artes. Estas son las mañanitas... Tenga a bien escuchar con nosotros su Bundeslied, su "Canción de la unión" en la composición de su mejor amigo de la tercera edad, Carl Friedrich Zelter. ¿Verdad que así es la música que le agrada?

Pero, ¿por qué frunce las cejas? Me pregunta por qué tantas caravanas, por qué le digo doctor. Pues, a tal señor, tal honor. ¿No se acuerda de que en su juventud se tituló en derecho, allá por el 1772, en la Universidad de Estrasburgo? Es verdad que no le aceptaron su tesis de doctorado por irreverente y provocativa, usted se sentía como un idealista revoltoso del 68 del siglo XX, ¿no es cierto? Pero conste que le permitieron defender una lista de 56 tesis redactadas en latín, y con esta réplica usted se recibió. Bueno, le diré Licenciado, si así lo prefiere, si bien sus colegas lo llamaban Doctor cuando usted empezó su brillante carrera de abogado que pronto dejó truncada. ¡Lástima por los reos injustamente acusados! Porque usted de veras sabía defenderlos con fervor pletórico. Pero tiene razón, los verdaderos estudios e investigaciones las emprendió después de egresar de la universidad. Mineralogía, física, química, zoología, botánica, su famosa Metamorfosis de las plantas. ¡Mire esta hoja! La recogi en Weimar, es de su árbol. Claro que recordamos su poema:

\section{Gingo biloba}

Dieses Baums Blatt, der von Osten 
Meinem Garten anvertraut, Gibt geheimen Sinn zu kosten, Wie's den Wissenden erbaut.

Ist es Ein lebendig Wesen, Das sich in sich selbst getrennt?

Sind es zwei, die sich erlesen, Daß man sie als Eines kennt?

Solche Frage zu erwidern, Fand ich wohl den rechten Sinn:

Fühlst du nicht an meinen Liedern, Daß ich Eins und doppelt bin?

$Y$ vea las traducciones que encontré en Argentina, la segunda en un parque junto a un árbol Gingko Biloba dedicado a usted. De la lejana China hasta la remota Argentina y usted en medio de los círculos concéntricos.

\section{Gingko Biloba}

La hoja de este árbol, confiado a mi jardín desde oriente, ofrece un sentido arcano que edifica a los sapientes.

¿Es un único ser vivo en sí mismo separado? ¿Son dos que se han elegido a que como uno los veamos?

Estas preguntas planteando he hallado el sentido puro. ¿No percibes en mis cantos que soy doble, que soy uno?

(Trad. Adan Kovacsics)

\section{Gingko Biloba}

La hoja de este árbol desde el Oriente a mi jardín venido, tal como al sabio placer gustar nos hace un oculto sentido.

¿Un ser viviente es, por sí mismo en sí mismo dividido o dos son que anhelando el ser de la unidad se han elegido?

Por fin hallé la clave con que pudo el enigma ser vencido: ¿acaso en mis canciones que uno y doble soy no has percibido?

(Trad. Martín Zubiría)

Científico poeta, claro que entendimos que no sólo no da una clase de botánica con esta planta prototípica. Como para usted cada fenómeno es parabólico nos presenta la hoja como símbolo del amor, dos que se sienten una, una que es doble. ¿Qué me dice, que me fije en la rima? Pues claro, allí está. Hasta en la forma usted escondió esta duplicidad con las 
rimas masculinas y femeninas alternadas, la estrofa hecha pareja. Este reto fue demasiado para los traductores.

¡Con cuántos científicos de su tiempo intercambió ideas, a cuántos influyó en su camino, como a los hermanos Humboldt! Y su célebre Teoría de los colores, ¿cómo la vería desde la perspectiva de hoy? Usted consideró que fue ésta su obra más importante. Le puedo asegurar que, aunque no le hayan concedido razón, la siguen tomando en cuenta. Usted tiene fama de buen traductor. Su traducción de $E l$ sobrino de Rameau y la retraducción al francés antes de que encontrara el original de Diderot parece novela de ficción. Usted goza de mucho prestigio como pintor y como crítico de arte. Lo que dijo y escribió sobre música también es considerable a pesar de que usted repetía cada cuando que no la entendía. Dicen que usted tocaba el piano, y nada mal; también alaban su voz: un armonioso bajo. Y no puede negar que escuchar música le era de vital importancia.

Señor Secretario, ¿podría usted decirme cómo encontró el tiempo para hacer todo lo que hizo en su vida? A los veintidós años ya se había titulado, a los 26 ya era ministro en la corte del condado de Weimar, y no sólo una cartera: minas, caminos, guerra, finanzas, además de la dirección del teatro, de las bibliotecas. No es de extrañarse que, después de diez años de lidiar con los problemas de este ministerio, usted se haya refugiado en Roma para vivir en el anonimato, la independencia y dedicado enteramente a sus estudios y su obra. ¿Caray, qué obra! El insuperable Fausto, el impactante Werther, las siempre actuales Afinidades electivas, su Wilhelm Meister que ha marcado la pauta para toda la novelística posterior, sus obras teatrales del "Sturm und Drang", Gotees y Egmont, de veras ¡qué ímpetu!, y las clásicas Ifigenia y Tasso, sus obras autobiográficas, Poesía y verdad, Viaje a Italia, no cabría la lista de todas las joyas que nos dejó. Pero, querido Maestro, lo que me arrebata más que nada es su poesía. En verdad, Don Alfonso Reyes tuvo razón cuando dijo: "Siempre para abordar a Goethe, el mismo ejercicio previo. Hay que ensanchar la cabeza". Leyendo sus versos, me doy cuenta de que nada humano le era ajeno. Como poeta, usted es realmente inagotable. Dicen que la poesía es un don de la adolescencia, entonces usted es un eterno adolescente. ¿Qué no bromeó usted mismo con sus repetidas pubertades? ¿Cuándo escribió su último poema, a los ochenta y dos años? Felicidades, maestro, y gracias, porque sus versos son expresiones de alegría, gozo, dolor, rebeldía, resignación, duda, fe, de lo nimio y de lo sublime, de lo divino y lo demoniaco, y, más que nada del amor, del amor en todas sus facetas.

Quien se adentra en sus lieder, baladas, himnos, elegías, epigramas, dísticos, parábolas, refranes, descubre a un Orfeo totalmente asombroso, 
a un hombre que, con o contra la corriente, supo conservar, durante toda su vida, una máxima libertad, un espíritu independiente, domado tan sólo por su propia voluntad de disciplina en beneficio de su obra.

Ya sé lo que me va a decir, Don Wolfgang, de desgraciados está el mundo lleno. Nunca faltan las malas lenguas. Que el niño demasiado petulante, que el estudiante demasiado estrafalario, que el abogado demasiado retórico, que el cortesano demasiado servil, que su excelencia altanera y fría, esposo de una mujer indigna, apátrida, ateo y cuántas cosas más. Deje que hablen. Ya sabe que las olas se arremeten contra la roca más alta. Usted mejor que nadie sabe que son medias verdades. $Y$ tenga en cuenta que hay más testimonios que lo defienden, que lo encomian, hablan de usted como la persona más encantadora, amable, ingeniosa, profunda, divina. Usted habrá notado el cambio en Wieland cuando lo llegó a conocer: "No le crea ni una palabra a esta dama, la Fama, de las maldades que vocifera". Varios amigos justifican su actitud reticente, dicen que usted tenía que protegerse ante las multitudes de curiosos que se apiñaban para conocerlo. Dicen que no fue frialdad, sino una sensibilidad exacerbada la que impedía que usted asistiera a los entierros de sus familiares y amigos. Dicen que no fue intolerancia o cerrazón ante el patriotismo de los románticos, sino su sabiduría y visión de una cultura mundial donde podríamos vivir en armonía y paz si supiéramos respetarnos mutuamente. Dicen que los criticones eran unos envidiosos. Pero si lo tachan de egoísta, confiéselo, hay algo de verdad, usted era egoísta en beneficio de su obra, no escatimó esfuerzos para llevarla a cabo. ¡Qué labor titánica terminar una obra de la magnitud del Fausto, a los ochenta y dos años! Mi sincero respeto, Maestro. $\mathrm{O}$, ¿será que usted, igual que su tocayo - ambos se llamaban Johann, cierto-, había firmado un pacto con el diablo para lograr tales gestas? Johann, Juan - de todos modos Juan te llamas. Con todo, usted se habrá quedado absuelto de la misma manera: "lo eterno femenino nos eleva a los cielos", grandiosas palabras con las que cierra la segunda parte del Fausto.

Hablando de lo eterno femenino, querido príncipe de los poetas, ile interesa lo que, el otro día, dijo Luis de Tavira de su magna tragedia? Que el Fausto es culto mariano, y por lo tanto, su obra más mexicana. Por qué no: La plegaria de Margarita dirigida a la virgen María es tan conmovedora como el "Ave María" de Schubert que se canta en todas las bodas mexicanas.

A propósito de Franz Schubert: qué lástima que usted aún no sabía apreciar a este su compositor congenial. En fin, por lo menos, a los ochenta años llegó a reconocer la belleza de "El rey de los alisos" puesto en mú- 
sica por Schubert. Usted le besó la frente a la guapa cantante y le agradeció su magnífica interpretación, y ella quedó tan encantada del éxito que exclamó: "Es el viejo más bello que jamás he visto y sería capaz de enamorarme mortalmente de él".

Bueno, venerado poeta mago, usted sabe mejor que nadie que ella no fue la única mujer enamorada de usted. Y usted dejó amplísimo testimonio de la importancia que tuvieron las mujeres en su creación poética. Me pregunto: en el lugar de cuál de todas ellas hubiera yo querido estar. Seguramente no en el de la mesera Gretchen de Francfort, que por tener dos años más que usted con sus escasos quince lo mete en líos y declara que lo consideraba todavía como un niño y lo quería como a un hermanito. Qué disgusto se llevó usted y la primera enfermedad causada por Cupido. Tampoco quisiera ser Kätchen en Leipzig, por la que usted, joven estudiante de diecisiete años, sufrió unos celos que lo llevaron al borde de la vida. Romántica la idea de tomar el papel de Federica Brion. Qué fervor, qué felicidad -y qué mala conciencia cuando la dejó. "Quien ha sido amada por Goethe, no podrá amar a otro", dijo la linda alsaciana, permaneció soltera y se hizo inmortal como la rosita de la pradera y la bella ingenuidad que provocó una fuerza expresiva totalmente nueva en la poesía. ¿Ser Lili, la niña de abolengo? ¿Ser Carlota Buff, la musa de Werther? ¿Ser la señora von Stein quien enseña al ministro impetuoso los austeros modales del buen cortesano y quien es la musa de sus versos más nobles de amor abnegado, resignado, de las miradas profundas, de tensiones insoportables y calma recobrada al contemplar la luna llena del valle? ¿O la legendaria Faustina en cuyas costillas usted medía los hexámetros de sus Elegias romanas? Es gustoso imaginarse el alivio que usted sintió en sus brazos. Ya se acercaba a los cuarenta años y por fin abrió los ojos, miró, palpó y gozó la belleza con todos sus sentidos. ¿O ser Christiane Vulpius que escandalizó a la buena sociedad de Weimar, su amante, madre de su hijo y finalmente esposa? Ella sabía darle el cariño y comodidad que tanto anhelaba, ¿no es así? O todas estas jovencitas encantadoras que le echaban ojitos, ellas fueron pasajeras pero los poemas que suscitaron imperecederos. Dicen que hasta a una emperatriz se le encendieron los ojos en estas miradas cruzadas, guardando, por supuesto, protocolo y decoro. No cabe duda de que usted fue un "mágico prodigioso". No, la mujer que yo hubiera querido ser es Marianne von Willemer. Sus lecturas lo llevaron a usted al oriente. Usted viajó a occidente a orillas del Rin, donde conoció a Marianne y juntos emprendieron este vuelo platónico identificándose con Hatem y Suleika de la poesía medieval persa, y así brotó su candente Diván occidental oriental. Y Marianne rimó al alimón, 
le salieron versos tan bellos que no vacilaste en publicarlos como tuyos. Yo tampoco me habría ofendido como las feministas de hoy que andan reclamando. Me habría sentido halagada de encontrar mis rimas en tu Diván, encargándole al viento que le transmita mis sentimientos:

Dile, pero dilo con modestia

Su amor es mi vida.

Sí, me hubiera gustado ser esta amada tuya que te hizo sentirte joven a pesar de tus canas, explotar el ingenio y fogosidad, escondiendo tu nombre en rimas no realizadas que me cantabas a mí:

Du beschämst wie Morgenröte

Jener Gipfel ernste Wand,

Und noch einmal fühlet Hatem

Frühlingshauch und Sommerbrand.
Como la aurora ruborizas tú de las cimas la seria pared y de nuevo siente Hatem aliento de primavera, fuego estival.

Vaya reto para el traductor.

Confiesa, poeta querido, que no siempre era la mujer lo que más te importaba, sino la veta que se iba abriendo en ti, dando paso a todas estas estos solaces:

Löscht ich so der Seele Brand

Lied es wird erschallen;

Schöpt des Dichters reine Hand,

Wasser wird sich ballen.
Apagando así del alma el ardor la canción se hará sonar; por la mano pura del poeta el agua se hará cristal.

Ya sé lo que me vas a decir: el amor no es ningún juego baladí. ¡Cuánto sufriste por culpa de Cupido! Cuántas veces te ha llevado al borde de la existencia. Pero tú mismo describiste tu "remedio casero": "Todo lo que me alegraba o me torturaba o de alguna manera me llamaba la atención, a lo largo de mi vida, he venido transformándolo en una imagen, en un poema, para volver a la serenidad y llegar a un buen término conmigo mismo". Te acuerdas de esta terrible enfermedad a los setenta y cuatro años cuando la niña Ulrike, de diecinueve años, no quiso casarse contigo y tu mejor amigo de la tercera edad, el músico Zelter, acudió a tu lecho y diario te leía tu poema "Elegía de Marienbad" y poco a poco te redimías y recobrabas el ánimo. Como tú dijiste a través de Tasso: "Cuando el hombre calla en su dolor, un dios me dio el don de decir lo que sufro".

Lo que me duele cuando pienso en tu poesía es que en el mundo hispánico hay pocos que la conocen y la aman. Rimaste una vez en unos ver- 
sos parabólicos que "los poemas son como vitrales", de fuera se ven pardos y sombríos. Pero si entras en la iglesia, se iluminan de colores e historias, empiezan a vibrar y vibras con ellos. Pues, parece que tus poemas traducidos al español son vitrales de fuera, no cobran vida. Sabes lo que dijo José Emilio Pacheco:

Goethe: Gedichte

Orbes de música verbal

Silenciados

Por mi ignorancia del idioma.

Tu poesía, una inmensa caja de música cerrada con llave. Y, la llave, ¿dónde podremos encontrarla? Tenemos que hacer votos porque se forme un proyecto de reunir tus más bellos versos en traducciones que hagan brillar tus vitrales de modo que se enciendan los ánimos de los lectores de lengua española. Y nos vamos a valer de la música para deleitarnos con tus flores siemprevivas.

Gracias, ilustre poeta, por habernos dado tanto. 